\title{
NUMERICAL MODELLING OF ICEBERG TOWING FOR WATER SUPPLIES-A CASE STUDY
}

\author{
By J. G. Joв* \\ (Department of Chemical Engineering, University of Adelaide, Adelaide, South Australia \\ 5 OOI)
}

\begin{abstract}
The towing of unprotected icebergs from the Antarctic continent $\left(66^{\circ} \mathrm{S}\right.$. $)$ to latitude $38^{\circ} \mathrm{S}$. has been simulated using an explicit hydrodynamic model and an extended two-dimensional melting model. It was found that nominal towing accelerations in excess of $2 \times 10^{-5} \mathrm{~m} \mathrm{~s}^{-2}$ were required to deliver ice over this route in most circumstances, and minimum energy consumptions were obtained at accelerations around ${ }^{10} \mathrm{O}^{-4} \mathrm{~m} \mathrm{~s}^{-2}$. Unprotected icebergs could be delivered with about $50 \%$ yield to latitude $38^{\circ} \mathrm{S}$., but the rate of deterioration in the warm waters indicates that protection would be required for longer journeys. The towing simulation was most sensitive to north-south current components, the total towing distance, and the rate of iceberg deterioration. Efforts directed towards locating suitable icebergs in the region of $50^{\circ} \mathrm{S}$. to $60^{\circ} \mathrm{S}$., and towards increasing knowledge of the changing current patterns in the Southern Ocean would be most valuable, as would a knowledge of the mechanisms and rates of deterioration of icebergs in warm seas.

RÉsumé. Modéle numérique du remorquage d'icebergs pour l'alimentation en eau -une étude de cas. On a simulé le remorquage d'icebergs non protégés depuis le continent Antarctique $\left(66^{\circ} \mathrm{S}\right.$.) à la latitude $38^{\circ} \mathrm{S}$. en utilisant un modèle hydrodynamique explicite en un modèle de fusion bidimensionnel. On a trouvé que les accélérations dépassant $2 \times \mathrm{IO}^{-5} \mathrm{~m} \mathrm{~s}^{-2}$ pour acheminer la glace sur tout l'itinéraire, dans la plupart des cas et les consommations minimum en énergie ont été obtenues autour de $10^{-4} \mathrm{~m} \mathrm{~s}^{-2}$. Des icebergs non protégés pouvant être acheminés avec un rendement d'environ $50 \%$ jusqu'à la latitude de $38^{\circ} \mathrm{S}$., mais la vitesse de destruction dans les eaux chaudes est telle qu'une protection serait nécessaire pour des voyages plus lointains. La simulation du remorquage est surtout sensible aux composantes Nord Sud des courants marins, à la distance de remorquage et à la vitesse de désagrégation de l'iceberg. Il serait utile de faire porter les efforts sur la localisation d'icebergs convenables dans la région des $50^{\circ}$ à $60^{\circ} \mathrm{S}$. et vers une meilleure connaissance des variations des courants marins dans l'Océan Antarctique, comme il serait bon de mieux connaître le mécanisme et la vitesse de désagrégation des icebergs dans les mers chaudes.
\end{abstract}

Zusammenfassung. Numerische Modelle für das Schleppen von Eisbergen zur Wasserversorgung - eine Fallstudie. Das Schleppen ungeschützter Eisberge vom antarktischen Kontinent $\left(66^{\circ} \mathrm{S}\right.$.) auf eine Breite von $38^{\circ} \mathrm{S}$. wurde mit Hilfe eines expliziten hydrodynamischen Modelles und eines erweiterten, zweidimensionalen Abschmelzmodelles simuliert. Es zeigt sich, dass zumeist Nenn-Schleppbeschleunigungen von mehr als $2 \times \mathrm{IO}^{-5} \mathrm{~m} \mathrm{~s}^{-2}$ benötigt werden, um Eis über diese Strecke zu befördern; der geringste Energieverbrauch ergibt sich bei etwa $\mathrm{IO}^{-4} \mathrm{~m} \mathrm{~s}^{-2}$. Ungeschützte Eisberge könnten mit einem Nutzeffekt von ca. $50^{\circ} \%$ in $38^{\circ}$ südlicher Breite gebracht werden, doch der Verfall in warmen Gewässern würde einem Schutz für längere Strecken erfordern. Die Schlepp-Simulation erwies sich als empfindlich gegen Nord-Süd-Komponenten der Meeresströme, gegen die Gesamtlänge des Schleppweges und die Verfallsrate der Eisberge. Anstrengungen zur Lokalisierung geeigneter Eisberge im Gebiet zwischen $50^{\circ}$ und $60^{\circ}$ Süd und zur besseren Kenntnis der wechselnden Strömungsmuster im Südlichen Ozean wären ebenso wertvoll wie die Kenntnis des Mechanismus und der Geschwindigkeit des Verfalls von Eisbergen in warmen Gewässern.

\section{Nomenclature}

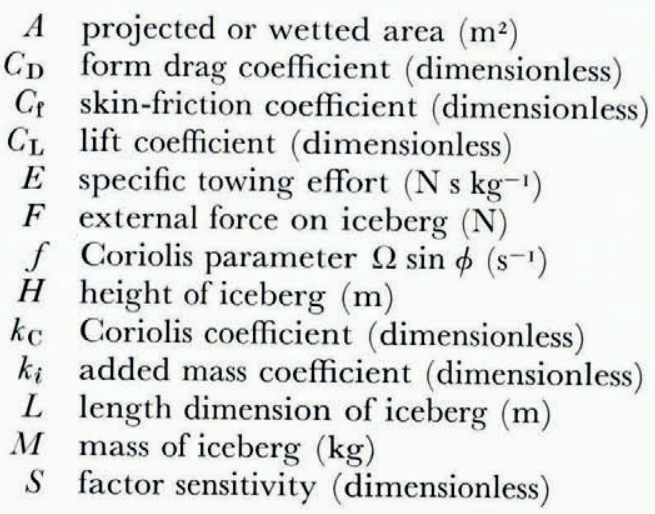

* It is with much regret that the International Glaciological Society has learnt of the death on 30 October 1978 of J. G. Job, a few days after correcting the proofs of this paper. 
$V \quad$ velocity of wind $\left(\mathrm{m} \mathrm{s}^{-1}\right)$

$x \quad x$ coordinate $(\mathrm{m})$

$y \quad y$ coordinate $(\mathrm{m})$

$z$ height above sea surface $(\mathrm{m})$

$\alpha$ angle between iceberg $y$-axis and direction of motion of iceberg

$\beta$ angle between direction of iceberg motion and north

$\psi$ angle between towing pull and iceberg $y$-axis

$\Omega \quad$ angular velocity of earth $\left(7.29 \times \mathrm{IO}^{-5} \mathrm{rad} \mathrm{s}^{-1}\right)$

$\phi$ latitude angle

$\rho$ fluid density $\left(\mathrm{kg} \mathrm{m}^{-3}\right)$

$\theta$ angle between wind direction and north

\section{Subscripts}

a refers to air

w refers to wetted area

wi refers to wind

$x$ denotes forces or velocities in the $x$-direction, lengths or areas projected on the $x$-direction and coefficients relevant to $x$-direction motion

$y$ denotes forces or velocities in the $y$-direction, lengths or areas projected on the $y$-direction and coefficients relevant to $y$-direction motion

\section{INTRODUGTION}

Considerable interest in the possibility of utilizing Antarctic icebergs for water supply to coastal regions has been generated by the work of Weeks and Campbell (1973) and also by Hult and Ostrander (1973). The latter authors studied a hypothetical tow of large, insulated iceberg trains from the Antarctic to southern California. Their assumption of effective insulation of the icebergs essentially eliminated deterioration through melting and calving from their analysis, so that hydrodynamic considerations were dominant in their simulation. However, the technology of insulation is arguably the most problematic aspect of the whole operation, so that the alternative approach of towing unprotected icebergs needs to be fully evaluated. On the other hand, Weeks and Campbell (r973) did model such an operation, where unprotected icebergs were towed to destinations in the southern hemisphere, but a number of important factors in iceberg deterioration were not included in their model. Since the viability of a towing operation would be dramatically affected by the total rate of ablation of the iceberg, it is important to estimate this rate with reasonable accuracy.

The work reported here includes the important melting mechanisms of bubble-assisted natural convection and wave attack, and accounts for the effects of non-uniform melting. In addition, wave radiation stresses and Coriolis forces were explicitly included in the force balance which determines the velocity of the iceberg. The inclusion of such factors makes very significant differences to the resultant calculated ice delivery and energy consumption.

The general towing trajectory studied is approximately equivalent to that studied by Weeks and Campbell, but a simplified environmental regime has been specified which gives rise to a quasi-one-dimensional trajectory. This makes it possible to isolate the sensitivity of the ice delivery results from each of the important environmental factors, and from the assumptions concerning the fluid dynamics of the motion of the iceberg and the heat transfer to it.

\section{General dynamic model}

The motion of the iceberg is modelled by the following force balance written in component form: 
$x$ direction:

$$
M\left(\mathrm{I}+k_{i x}\right) \ddot{x}=F_{x}(t)+2 M k_{\mathrm{C} y} f y-\frac{\rho}{2}\left[\dot{x}\left\{C_{\mathrm{D} x} A_{y}|\dot{x}|+C_{\mathrm{f}} A_{\mathbf{w}}\left(\dot{x}^{2}+\dot{y}^{2}\right)^{\frac{1}{2}}\right\} \pm C_{\mathrm{L} y} A_{x} \dot{y}^{2}\right] ;
$$

$y$ direction:

$$
M\left(\mathrm{I}+k_{i y}\right) \ddot{y}=F_{y}(t)-2 M k_{\mathrm{C} x} f x-\frac{\rho}{2}\left[\dot{y}\left\{C_{\mathrm{D} y} A_{x}|\dot{y}|+C_{\mathrm{f}} A_{\mathrm{w}}\left(\dot{x}^{2}+y^{2}\right)^{\frac{1}{2}}\right\} \pm C_{\mathrm{L} x} A_{y} \dot{x}^{2}\right] .
$$

The terms on the right-hand side are, in order, the sum of all external forces (wind, wave, and towing force) independent of the motion of the iceberg, the Coriolis force, form drag, skin friction drag, and normal (lift) forces.

A number of assumptions are implicit in the writing of such a dynamic model. The most important ones are:

(i) The motion can be described by a Coriolis-induced perturbation to a conventional high-Rossby-number dynamic model.

(ii) The motion is translational but without rotation, where the velocity of the iceberg with respect to the water can be represented by a single translation vector.

(iii) The Coriolis force can be written unambiguously in terms of the relative velocity of the iceberg with respect to water, and is modified by an empirical coefficient $k_{\mathrm{C}}$.

(iv) The whole of the attitude-dependent effects on hydrodynamic drag can be absorbed by considering the drag components to arise from the corresponding velocity component and a constant drag coefficient.

\section{Simplification of the model}

The equations can be integrated by any normal stepwise procedure, but, with a necessarily small time step, excessive computer time is required for the simulation of a long towing path. The steady-state equations are obtained by equating accelerations to zero. The assumption of steady winds (a function of latitude only) is consistent with the use of a steady-state model.

The coordinate axes can be oriented as required, and the orientation which achieves the greatest simplification is one which is fixed with respect to an axis of the iceberg, thus making the drag coefficients independent of the orientation of the iceberg. The assumption that the iceberg has two planes of symmetry perpendicular to the $x y$ plane has the convenience that the lift coefficients are zero, as defined. The most suitable plan form with these properties is an ellipse, but the assumption of other forms (e.g. a rectangle) would not affect markedly the results obtained.

\section{Specification of environmental forces}

The direct wind force was specified as follows:

$$
\begin{aligned}
& F_{\mathrm{wi} x}=\frac{\rho_{\mathrm{a}}}{2} \sin (\theta+\alpha-\beta)\left[L_{y} C_{\mathrm{Da} x}|\sin (\theta+\alpha-\beta)| \int_{0}^{H} V_{z^{2}} \mathrm{~d} z+C_{\mathrm{fa}} A_{\mathrm{wa}}\right], \\
& F_{\mathrm{wi} y}=\frac{\rho_{\mathrm{a}}}{2} \cos (\theta+\alpha-\beta)\left[L_{x} C_{\mathrm{Da} y}|\cos (\theta+\alpha-\beta)| \int_{0}^{H} V_{z^{2}} \mathrm{~d} z+C_{\mathrm{fa}} A_{\mathrm{wa}}\right],
\end{aligned}
$$

where $V_{z}=V_{\mathrm{IO}}(z / \mathrm{IO})^{1 / 7}, \alpha=\tan ^{-1}(x / y)$, and the various angles are positive as shown in Figure $\mathbf{I}$. 


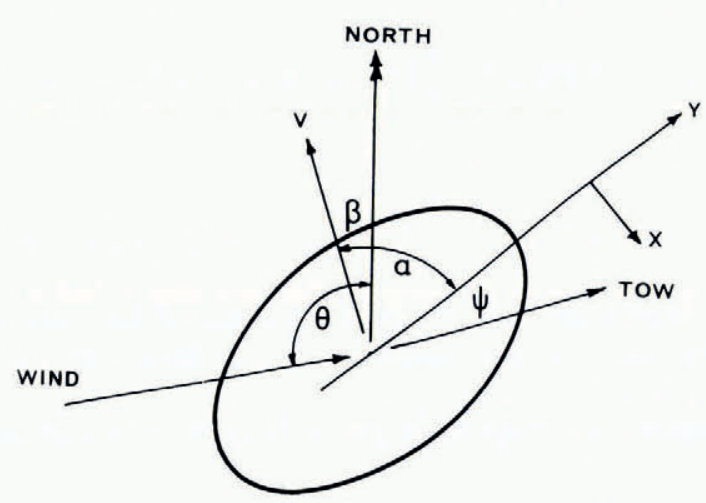

Fig. 1 . The iceberg in its frame of reference for the dynamic model.

The wave force was calculated as that arising from the reflection of the waves of a fully risen sea from the vertical face of an iceberg, including the effect of a wavelength spread (personal communication from K. T. Spillane). This was modified by an arbitrary latitudedependent factor to allow for the effects of sea ice and the inconstancy of wind direction:

$$
\begin{aligned}
& F_{\text {wave } x}=0.3^{8} L_{y} V^{4} \sin (\theta+\alpha-\beta)|\sin (\theta+\alpha-\beta)|, \\
& F_{\text {wave } y}=-0.3^{8} L_{y} V^{4} \cos (\theta+\alpha-\beta)|\cos (\theta+\alpha-\beta)| .
\end{aligned}
$$

It is interesting to note that on the above estimates, the wave radiation force becomes comparable with the direct wind force at wind velocities over $10 \mathrm{~m} \mathrm{~s}^{-\mathrm{I}}$. The mean wind used in the towing simulations was obtained by taking a zonal average of wind data from all sources between $70^{\circ} \mathrm{E}$. and $150^{\circ} \mathrm{E}$. longitude, as reported by Eyre (1972).

Although the general circumpolar current has a marked easterly transport there are probably significant circulatory motions with a time scale of weeks or months, and an actual towing operation may well be able to pick significant favourable currents to provide a natural northerly component to the motion. Nevertheless, it was assumed in this simulation that there was in fact no meridional component, so that transport was neither helped nor hindered by the general ocean circulation.

The specification of drag coefficients and other important shape-related factors is not straightforward, since the available information is sparse and somewhat equivocal. Job ([ ${ }^{{ }}$978]) has discussed this topic in its application to the present simulation. The form drag coefficients $C_{\mathrm{D}}$ assumed are in the range 0.35 to 0.9 depending on shape, the friction drag coefficients $C_{\mathrm{f}}$ in the range 0.002 to 0.006 , and the Coriolis coefficients $k_{\mathrm{C}}$ in the range 0.6 to I.3.

When the appropriate coefficients, environmental forces, and towing force are inserted into the dynamic model, the resulting equations can generally be solved by an iterative process for the velocity components with respect to the mean current, $\dot{x}$ and $\dot{y}$. This solution requires the arbitrary specification of either the orientation of the iceberg or the direction of the resultant velocity of the iceberg, in order to fix the system in a geographical frame of reference.

The pseudo-one-dimensional trajectory allows the convenient specification of the direction of motion with respect to the current, i.e. due north. On occasion, where the winds were unfavourable and the towing force small, a simple northward motion was not possible, and a search had to be made for other possible directions which had a significant northerly component of motion. 
ICEBERG MELTING AND DETERIORATION

In towing an unprotected iceberg, the rates of ablation and calving are critical in the determination of whether significant quantities of ice will be delivered. Previous authors have confined their attentions to an ablation mechanism of turbulent, forced-convective heat transfer to a homogeneous plane surface, a mechanism which is fairly well understood.

The important mechanisms of deterioration which can be foreseen are:

(i) Turbulent, forced-convection ablation of the bottom and immersed portions of the sides due to the net motion of the iceberg through still water, enhanced by surface macro-roughness or waviness.

(ii) Buoyancy-induced natural convection along the sides, enhanced by the buoyancy of air bubbles released along with the melting ice.

(iii) Undercutting of the sides by wave action, followed by top calving.

(iv) Subsurface calving due to the upthrust on large underwater shelves formed by other ablation mechanisms.

(v) Differential melting along cracks or low-density planes in the iceberg, leading to further calving.

(vi) Convection caused by wallowing and possible overturning following a large calving event.

(vii) Top melting by interception of solar radiation and convection with the atmosphere.

(viii) Possible break-up of the iceberg due to thermal stresses induced following calving in warm waters.

The influence of the several melting mechanisms is also further complicated by two important factors. These are the markedly lower density of the ice in the upper portion of the berg (Crary and others, I962, p. I I5), and the uncertainty regarding the likely salinity profile in the water close to the ice surface. This last factor affects both the effective temperature difference which drives the heat transfer, and the magnitude of the buoyancy forces which drive the strong natural convection.

Turbulent forced convection was modelled using the well-known Eckert and Drake flat plate correlation (Eckert and Drake, i959, p. 215), after modification for surface waviness (Ashton, 1972), initial ice temperature, and finite interfacial velocity (Vanier and Tien, 1968).

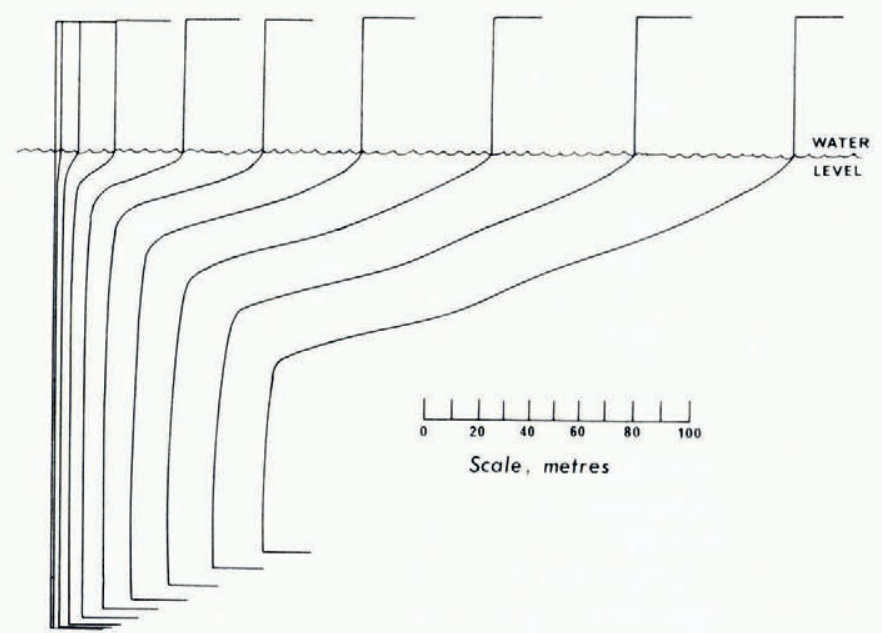

Fig. 2. Recession of the side face of an iceberg for a typical simulated tow. (4 $\mathrm{km}^{2}$ equi-dimensional iceberg at $5 \times 10^{-5} \mathrm{~m} \mathrm{~s}^{-2}$ nominal towing acceleration.) Profiles are plotted at time intervals of $5 \times 1 \mathrm{O}^{5} \mathrm{~s}$. 


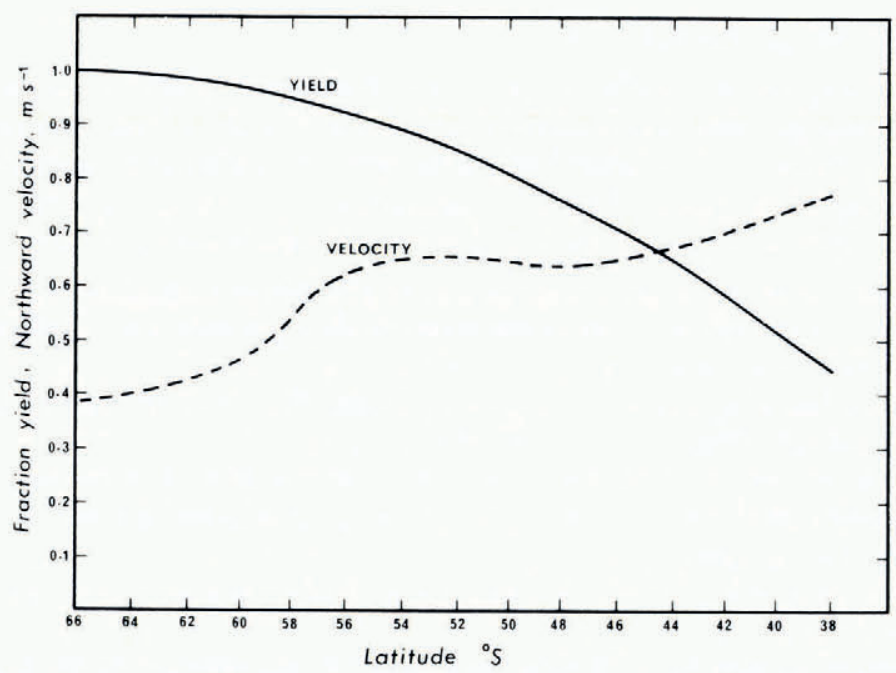

Fig. 3. Velocity trajectory and yield for a typical simulated tow. $\left(4 \mathrm{~km}^{2}\right.$ equi-dimensional iceberg at $5 \times 10^{-5^{*}} \mathrm{~m} \mathrm{~s} \mathrm{~s}^{-2}$ nominal towing acceleration.) Transit time was $6_{3} d$.

Natural convection was modelled using a well-established correlation (McAdams, I954, p. I 72) where the effective buoyancy contribution was modified by the presence of air bubbles (Konsetov, I966). The influence of these bubbles on the Prandtl number of the sea-water was also included (Batchelor, I 967 , p. 253). Wave action was modelled crudely by considering the melting action as approximated by forced convection corresponding to the induced swash velocities which can be estimated to prevail. Top calving was assumed to take place concurrently with this undercutting at the water line. The other five deterioration mechanisms listed above were not included in this simulation.

It is clear that the effects of low ice density in the upper parts of the berg, of buoyancy induced by the released air bubbles, of wave action, and of the vertical temperature gradient in the surrounding water, combine to produce a concentrated attack along the sides of the upper parts of the iceberg. It was therefore essential to model iceberg ablation as a function of depth. The development of a wave-cut platform introduces further complications, since the direction of ablation, being normal to the ice surface, is no longer horizontal on the sides. The effectiveness of natural convection is also influenced by surface inclination (Lloyd and others, 1972).

The recession of the profile of an iceberg resulting from these combined influences is presented for a typical simulation run in Figure 2. The corresponding yield and northwardtow velocities are shown in Figure 3. It is noteworthy that the rate of mass loss calculated here is many times greater than that obtained by considering forced convection alone, and is roughly comparable with that observed by Kollmeyer (i966).

\section{TOWING SIMULATION}

The formulation of the equations of motion in terms of the iceberg velocity with respect to the current suggests an important simplification for the towing route. A constant bearing can be taken for this velocity with respect to the current, and any current component in this direction added. This allows environmental conditions (wind and current speed and direction, and sea temperature) to be specified simply as functions of latitude, and the sensitivity of the total ice delivery to variations from the standard condition to be easily isolated. This is one way of handling the large number of variables which need to be included. 
The simulation has been performed for transport from $66^{\circ} \mathrm{S}$. to $38^{\circ} \mathrm{S}$. latitude, corresponding to a possible destination on the southern coast of Australia. The results may therefore be directly compared with those of Weeks and Campbell (r973).

The towing operation was assumed to be performed at constant power, which is slightly different from the constant thrust assumption of previous workers. For a certain combination of assumptions regarding initial iceberg size and shape, towing power, and environmental and other factors, the height out of water and the shape coefficients were calculated, and the velocity of the iceberg was computed (assumed constant for the standard time interval of $5 \times \mathrm{IO}^{4} \mathrm{~S}(\mathrm{I} 3.9 \mathrm{~h})$ ). After each time interval, melting decrements over the vertical profile and the undersurface were calculated, and the iceberg mass, flotation level, and all shape coefficients were recalculated. When the destination latitude was reached, the ice yield and energy consumption parameters were calculated.

\section{ICE DELIVERY}

The result of most importance is the volume of ice delivered as a function of iceberg size and towing force. Four sizes of iceberg were selected for examination: $1.5,4,7$, and $10 \mathrm{~km}^{2}$ of initial plan area, and two different shapes were used: equi-dimensional (circular plan) and a $3:$ I elliptical plan. This is the lower part of the range studied by Weeks and Campbell (1973) who considered icebergs up to $100 \mathrm{~km}^{2}$ initial plan area.

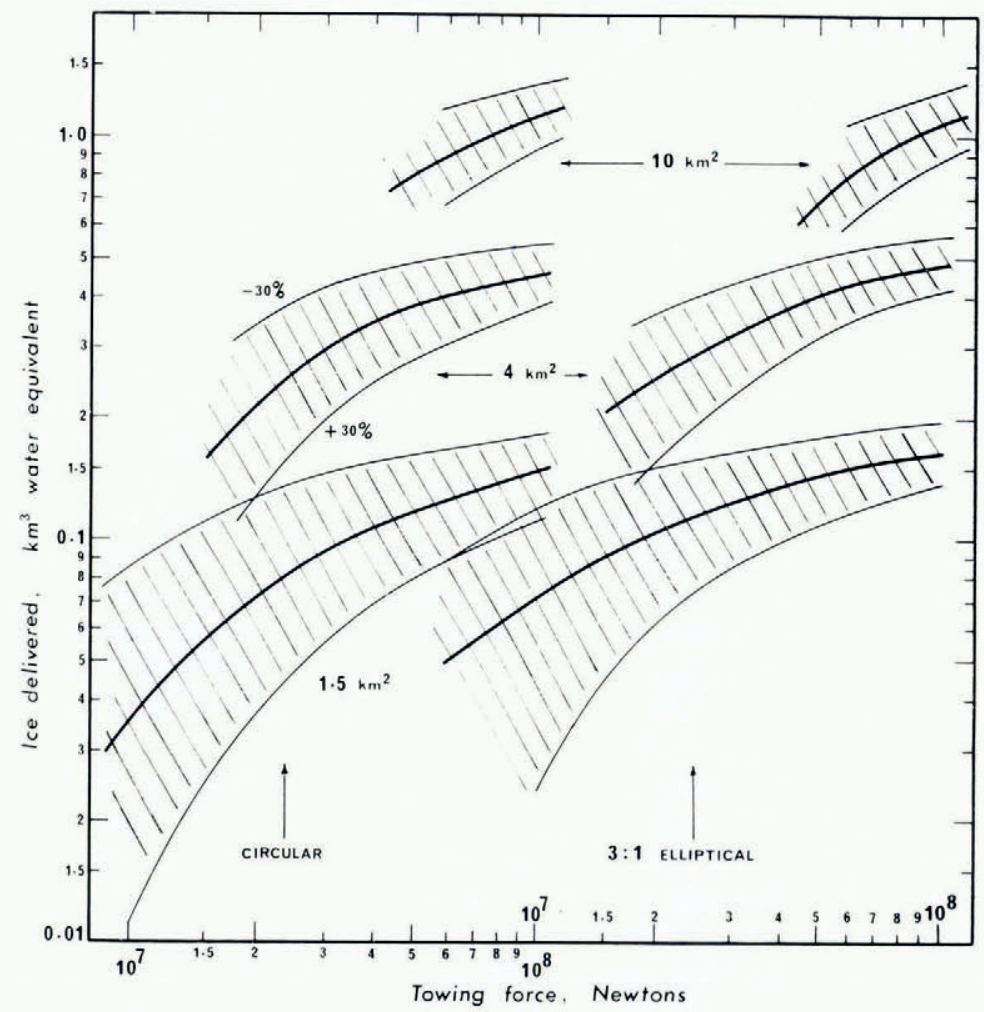

Fig. 4. Quantity of ice delivered from three initial sizes of iceberg $10 \mathrm{~km}^{2}, 4 \mathrm{~km}^{2}$, and $1.5 \mathrm{~km}^{2}$ plan area, corresponding to $I .96 \mathrm{~km}^{3}, 0.78 \mathrm{~km}^{3}$, and $0.29 \mathrm{~km}^{3}$ water equivalent respectively, and two shapes, as a function of mean towing force. The effect on ice delivery of $a \pm 30 \%$ variation in total melting rate is shown. 
A number of values of tug power were used, generally in the range 50 to $\mathrm{I}$ ooo MW, corresponding approximately to the range 5 to $100 \mathrm{MN}$ (500 to 10000 tons) of towing pull. This compares with the range 2 to $20 \mathrm{MN}$ which was considered by Weeks and Campbell. It was found necessary to use such large towing forces because lesser forces gave rise to several problems. These included poor performance under unfavourable winds at high latitudes and iceberg instability arising from excessive melting during the later part of the journey.

A useful measure of towing effect is the "nominal towing acceleration", defined here as the ratio of the time mean of the towing force divided by the initial mass of the iceberg. Values of towing acceleration less than about $2.5 \times \mathrm{IO}^{-5} \mathrm{~m} \mathrm{~s}^{-2}$ were not useful for the journey from $66^{\circ} \mathrm{S}$. Consideration of the likely wind and wave forces under gale conditions and the possibility that an adverse current may have to be headed at times, suggests that this acceleration would be a minimum requirement. This corresponds to the suggestion by Weeks and Campbell (1973) that a desirable minimum towing force would be that capable of maintaining a towing velocity of $0.25 \mathrm{~m} \mathrm{~s}^{-1}$.

The bold central lines in Figure 4 indicate the gross quantities of ice that could be delivered under the central assumptions of the model for three of the iceberg sizes. The simulation predicts that the proportion of the original iceberg which is delivered is a strong function of the towing force. This result is in contradiction to the results of Weeks and Campbell, who found that the percentage yield was almost independent of the towing force. The difference arises from the fact that the principal ablation mechanisms modelled here are essentially independent of the iceberg velocity. On the other hand, the conclusion that the percentage yield is not a strong function of the initial size and shape is in general agreement with Weeks and Campbell, at least over the range of size studied here.

Figure 4 also shows the effect on ice delivery of varying the assumptions which determine the overall melting rate, by $+30 \%$ and $-30 \%$ respectively. This variation makes a drastic difference to the ice delivery, which emphasizes the need for a realistic prediction of deterioration rates. In a similar manner, the ice delivery under varying assumptions of form drag coefficients, Coriolis coefficients, towing distance, and meridional current component were computed, and the results are analysed in terms of a "sensitivity factor" in a later section.

\section{TOWING EFFORT AND ENERGY CONSUMPTION}

The assessment of a scheme of this nature depends essentially upon the estimation of technical feasibility and economic viability. The predictions of ice delivery volumes for different towing forces as presented in the previous section are relevant to the assessment of the technical feasibility. From the point of view of economics, the most important single factor is the unit cost of water delivery, including conversion and shore facilities. The towing costs. are clearly an important part of this unit cost, and they have been estimated in previous work (Weeks and Campbell, I973; Hult and Ostrander, I973). A complete economic analysis of the towing stage is however hardly justified at this stage, given the approximate state of our knowledge. It is also markedly affected by assumptions regarding interest rates, fuel costs, and the like, which are external to the study.

On the other hand, consideration of the cost components involved indicate that the energy consumed per unit of ice delivered is of central importance, since many costs are directly proportional to the specific energy consumption. The energy consumption is however, markedly affected by the efficiency of the towing method employed. The essential difficulty of the particular iceberg towing operation can be isolated by calculating a "specific towing effort" $E$, defined here as the time-mean product of towing force and time, divided by the mass of ice delivered, in units of $\mathrm{N} \mathrm{s} \mathrm{kg}^{-1}$. Having estimated the value of $E$ for a particular towing job, this can be simply converted to a specific energy consumption by multipying by the power-to-thrust ratio appropriate to the type of towing apparatus employed. This ratio. 
has values of around ro $\mathrm{W} \mathrm{N}^{-1}$ for conventional tugs. If desired, an all-up unit-energy cost can be applied to this specific energy consumption to obtain an estimate of the unit delivery cost of ice. Some results are presented in this way in Figure 5 , and this makes clear several important points:

(i) For the trip from $66^{\circ} \mathrm{S}$., there is a well-defined optimal towing force for each size and shape, which minimizes the total towing effort per unit mass of ice delivered. This optimal towing acceleration is in the region of $\mathrm{IO}^{-4} \mathrm{~m} \mathrm{~s}^{-2}$.

(ii) The elongated iceberg shape is considerably more efficient than the equi-dimensional shape, but the difference is less significant for the larger sizes.

(iii) Very much less effort is required to tow icebergs from $50^{\circ} \mathrm{S}$., and the specific towing effort drops off continuously as the towing acceleration is reduced. The results for very low towing accelerations are only of academic interest because of the requirement for effective control under adverse conditions.

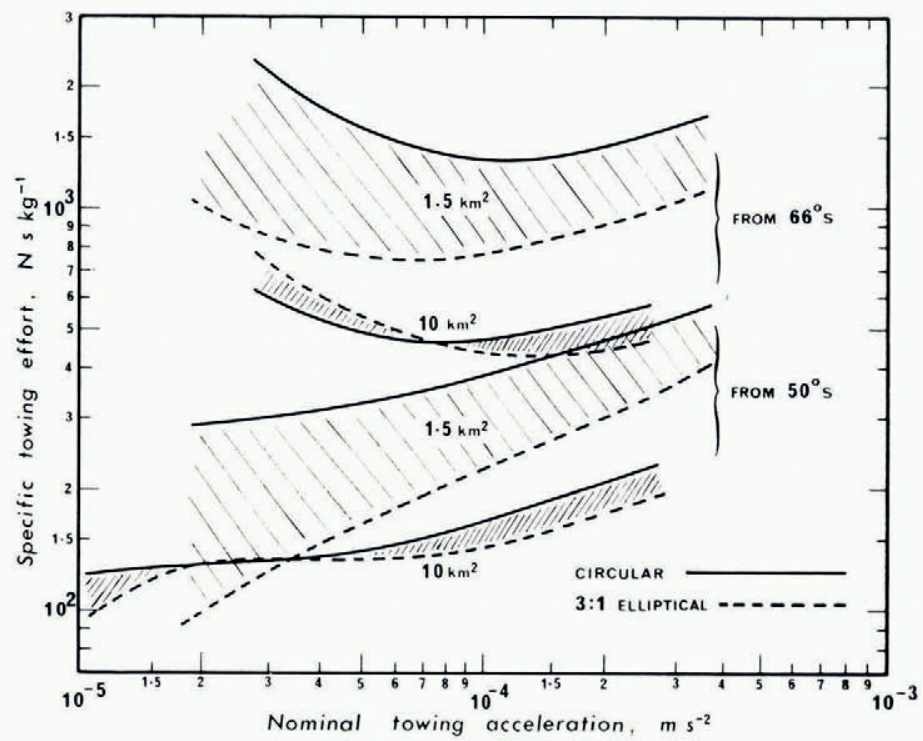

Fig. 5. Specific towing effort required for the delivery of ice to $38^{\circ} \mathrm{S}$. from $66^{\circ} \mathrm{S}$. and $50^{\circ} \mathrm{S}$. for two initial iceberg sizes and two shapes as a function of the nominal towing acceleration.

\section{OVER-ALL SENSITIVITY FAGTORS}

A variance analysis could be used to separate out the important variables and their interactions, but a highly simplified approach is presented here. A sensitivity factor $S$ is defined for a set of standard conditions of all parameters (except parameter $P$ ) by the following:

$$
S=\left(\frac{\left(E_{\mathrm{I}} E_{2}\right)^{\frac{1}{2}}}{E_{\mathrm{I}}}-\mathrm{I}\right) /\left(\frac{\left(P_{\mathrm{I}} P_{2}\right)^{\frac{1}{2}}}{P_{\mathrm{I}}}-\mathrm{I}\right),
$$

where $E_{1}$ and $E_{2}$ are the lower and higher values of the specific towing effort, and $P_{1}$ and $P_{2}$ are the lower and higher values of the parameter $P$ respectively. Sensitivity factors have been calculated for the standard condition of an equi-dimensional iceberg with a nominal towing acceleration of $5 \times \mathrm{IO}^{-5} \mathrm{~m} \mathrm{~s}^{-2}$ (Table I). 
TABle I. CALGUlated SENSITIVITY FACTORS For VARIOUS PARAMETER AND ICEBERG AREA CHANGES

\begin{tabular}{|c|c|c|c|}
\hline Parameter varied & $\begin{array}{c}\text { Initial } \\
\text { iceberg area } \\
\mathrm{km}^{2}\end{array}$ & $\begin{array}{l}\text { Sensitivity } \\
\text { factor }\end{array}$ & 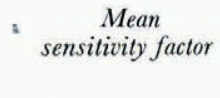 \\
\hline $\begin{array}{l}\text { Coriolis } \\
\text { coefficients }\end{array}$ & $\begin{array}{c}1.5 \\
4 \\
10\end{array}$ & $\begin{array}{l}0.4^{1} \\
0.74 \\
0.9^{1}\end{array}$ & o.69 \\
\hline $\begin{array}{l}\text { Form drag } \\
\text { coefficient }\end{array}$ & $\begin{array}{c}1.5 \\
4 \\
10\end{array}$ & $\begin{array}{l}1.22 \\
0.28 \\
0.08\end{array}$ & 0.53 \\
\hline Melting rate & $\begin{array}{l}1.5 \\
4 \\
10\end{array}$ & $\begin{array}{l}3.06 \\
1.08 \\
0.44\end{array}$ & I. 53 \\
\hline Towing distance & $\begin{array}{l}1.5 \\
4 \\
\text { IO }\end{array}$ & $\begin{array}{l}2.33 \\
1.69 \\
1.69\end{array}$ & 1.90 \\
\hline $\begin{array}{l}\text { Meridional current } \\
\text { component }\end{array}$ & $\begin{array}{c}1.5 \\
4 \\
10\end{array}$ & $\begin{array}{l}12.7 \\
2.44 \\
1.77\end{array}$ & 5.64 \\
\hline $\begin{array}{l}\text { Towing } \\
\text { acceleration }\end{array}$ & $\begin{array}{c}1.5 \\
4 \\
10\end{array}$ & $\begin{array}{l}0.5^{2} \\
0.11 \\
0.30\end{array}$ & $0.3^{1}$ \\
\hline
\end{tabular}

Some important conclusions follow from such an analysis. Current, towing distance, and melting rate each have a disproportionately great effect on the towing effort. It is clear from this that it would be very worthwhile to expend considerable effort in locating icebergs well north of the Antarctic continent when a tow to $38^{\circ} \mathrm{S}$. is under consideration. A greater knowledge of actual currents at the time of the tow could be of great assistance if it is possible to avoid unfavourable regions and to take advantage of favourable northward currents. It is also vital to obtain better information on the behaviour and deterioration of icebergs in warm seas.

MS. received I9 December 1977

\section{REFERENCES}

Ashton, G. D. 1972. Turbulent heat transfer to wavy boundaries. (In Landis, R. B., and Hordemann, G. J., $e d$. Proceedings of the 1972 Heat Transfer and Fluid Mechanics Institute. Stanford, Calif., Stanford University Press, p. 200-13.)

Batchelor, G. K. 1967. An introduction to fluid dynamics. Cambridge, University Press.

Crary, A. P., and others. 1962. Glaciological studies of the Ross Ice Shelf, Antarctica, 1957-1960, by A. P. Crary, E. S. Robinson, H. F. Bennett and W. W. Boyd, Jr. IGY Glaciological Report Series (New York), No. 6.

Eckert, E. R. G., and Drake, R. M. I959. Heat and mass transfer. New York, McGraw-Hill Book Co., Inc.

Eyre, W. S. I972. The spherical harmonic analysis of global wind stress field and atmospheric angular momentum. Flinders University of South Australia. Flinders Institute of Atmospheric and Marine Sciences. Research Report No. 6.

Hult, J. C., and Ostrander, N. C. 1973. Antarctic icebergs as a global fresh water resource. Santa Monica, Calif., Rand Corporation. (R-1 255-NSF.)

Job, J. G. [ [ ${ }^{\mathrm{I}} \mathrm{I} 978$.] Yields and energetics in moving unprotected icebergs to southern continents. (In Husseiny, A. A., ed. Iceberg utilization. Proceedings of the first International Conference and Workshops on Iceberg Utilization for Fresh Water Production, Weather Modification and Other Applications held at Iowa State University, Ames, Iowa, USA, October 2-6, 1977. New York, etc., Pergamon Press, p. 503-27.)

Kollmeyer, R. D. 1966. Interim report on iceberg deterioration. U.S. Coast Guard Oceanographic Report No. II, p. $4^{\mathrm{I}-64}$.

Konsetov, V. V. ig66. Heat transfer during bubbling of gas through liquid. International fournal of Heat and Mass Transfer, Vol. 9, No. 10, p. $1103-08$.

Lloyd, J. R., and others. I972. Laminar, transition and turbulent natural convection adjacent to inclined and vertical surfaces, by J. R. Lloyd, E. M. Sparrow and E. R. G. Eckert. International fournal of Heat and Mass Transfer, Vol. I5, No. 3, p. 457-73.

McAdams, W. H. I954. Heat transmission. Third edition. New York, etc., McGraw-Hill Book Co., Inc. (McGrawHill Series in Chemical Engineering.)

Vanier, C. R., and Tien, C. I968. Effect of maximum density and melting on natural convection heat transfer from a vertical plate. Chemical Engineering Progress Symposium Series, Vol. 64, No. 82, p. 240-54.

Weeks, W. F., and Campbell, W. J. 1973. Icebergs as a fresh water source: an appraisal. Journal of Glaciology, Vol. 1 2, No. 65 , p. 207-33. 